\title{
Sexual Behaviour and Mating System of Botryotinia fuckeliana, Teleomorph of Botrytis cinerea
}

\author{
By FRANCO FARETRA, * EMMANUELE ANTONACCI AND \\ STEFANIA POLLASTRO \\ Dipartimento di Patologia vegetale, Università degli Studi di Bari, Via G. Amendola 165/a, \\ 70126 Bari, Italy
}

(Received 18 February 1988)

Analysis of 213 field isolates of Botrytis cinerea and 240 ascospore isolates of its sexual form Botryotinia fuckeliana indicated that sexual compatibility of this fungus is controlled by a single mating type gene with two alleles. Most isolates were heterothallic, that is, they were self-sterile and able to produce ascospore progeny when crossed with reference strains carrying the mating type gene $M A T 1-1$ or $M A T 1-2$. About $16 \%$ of the field isolates and $6 \%$ of the ascospore progeny were homothallic, that is, self fertile and compatible with both $M A T 1-1$ and $M A T 1-2$ strains. Both mating types are widespread in nature. The close association of MAT1-1 and MAT1-2 field isolates on various hosts in several regions of Italy shows that sexual reproduction and meiotic recombination might be an important source of genetic variation in this pathogenic fungus.

\section{INTRODUCTION}

Botrytis cinerea Pers. is the agent of 'grey mould', a common disease of many economically important plants in temperate areas of the world. In earlier investigations, the teleomorphic stage of this fungus, Botryotinia fuckeliana (de Bary) Whetz., was obtained under controlled environmental conditions in the laboratory (Faretra \& Antonacci, 1987) and the procedure for producing apothecia was improved (Faretra et al., 1988). However, the methods used in these investigations were unable to provide information on this organism's sexual behaviour and mating system.

Sexual reproduction of fungi included in the family Sclerotiniaceae was unknown until the early 1930s. Whetzel (1929) suggested that the microconidia could act as male gametes in the same way as the pycniospores or spermatia of rust fungi. Drayton (1932) obtained apothecia of Stromatinia gladioli (Drayt.) Whetz. by placing microconidia from one isolate on the receptive structures that developed from the stromata of another, and he demonstrated that there were two mating types of $S$. gladioli, sexual reproduction occurring only when pairs of strains from two different groups of isolates were intercrossed. The inter-group fertility, intra-group sterility and self-sterility of Drayton's isolates are features of a heterothallic fungus.

In the family Sclerotiniaceae self-fertility has been found in various species of the genera Sclerotinia Fckl. (Coe, 1944; Drayton \& Groves, 1943; Groves \& Bowerman, 1955; Henson, 1935; Keay, 1939), Lambertella Höhnel (Whetzel, 1943), Ciboria Fckl., Ciborinia Whetz., Rutstroemia Karst., Septotinia Whetz., Verpatinia Whetz. et Drayt. (Groves \& Elliott, 1961), and Monilinia Honey (Ezekiel, 1924; Harada, 1977; Willetts \& Harada, 1984). As pointed out by Lorbeer (1980), therefore, it should not be surprising to find self-fertility among isolates of Botryotinia species. Indeed, homothallic behaviour has been observed in Botryotinia globosa Buchw: (Buchwald, 1953), Botryotinia porri (Beyma) Whetz. (Elliott, 1964) and Botryotinia ricini (Godfrey) Whetz. (Godfrey, 1923). However, Botryotinia ricini has a relationship with an anamorphic stage that does not belong to the genus Botrytis, and it has been placed in the genus Amphobotrys by Hennebert (1973). 
There is also evidence for self-sterility and heterothallism in species of Botryotinia. Drayton (1937) and Drayton \& Groves (1952) obtained apothecia of Botryotinia convoluta Drayt. and Botryotinia narcissicola (Gregory) Buchw., respectively, by crossing different isolates. Hennebert \& Groves (1963) showed that there are two mating types of Botryotinia ranuncoli Hennebert et Groves, and that isolates are self-sterile. Monoconidial isolates of Botryotinia squamosa ViennotBourgin fell into two groups of sexual compatibility, and the compatibility difference segregated $1: 1$ among ascospore progeny from four different crosses (Bergquist \& Lorbeer, 1972); these authors concluded that mating compatibility was under the control of a single gene with two alleles.

There is scant information on the sexual compatibility and mating types of Botryotinia fuckeliana. Groves \& Loveland (1953) carried out crosses between monoascospore cultures derived from isolates of Botrytis cinerea collected from diseased plants in Switzerland and Canada and concluded that the fungus was heterothallic. In further experiments they also observed that field isolates of the fungus obtained from grapes in California were self-fertile but believed such cultures to be mixtures of isolates of different mating type. More recently, Lorenz \& Eichhorn (1983) found homothallic and heterothallic cultures among isolates collected from grapevine in Germany as well as among their monoascospore offspring.

This paper reports the results of mating experiments with field isolates of Botrytis cinerea and ascospore progeny of Botryotinia fuckeliana. The aims of the investigation were to clarify the mating system and sexual compatibility of the fungus and to determine a suitable methodology for genetic studies.

\section{METHODS}

The field isolates of Botrytis cinerea (prefixed WS) were obtained from naturally infected plants in 1985-1987 (Table 4). These isolates were maintained on slants of solid Czapek medium at $5^{\circ} \mathrm{C}$ and periodically transferred to fresh medium. Monoascospore isolates of Botryotinia fuckeliana with the prefix SAS were derived from individual asci in a previous investigation (Faretra \& Antonacci, 1987). The other monoascospore isolates were random progeny from crosses of field isolates. All monoascospore cultures were maintained on slants of potato/sucrose agar.

The morphological features of the isolates were assessed after $10 \mathrm{~d}$ growth on slants of potato/dextrose agar in the dark at $22 \pm 1{ }^{\circ} \mathrm{C}$. They were classified as 'sclerotial type', 'mycelial type' and 'conidial type', these being the three morphotypes recognized by Paul (1929). Intermediate designations were used for isolates with less clear-cut morphotypes.

The methodology of Faretra \& Antonacci (1987) was used to make earlier crosses between the field isolates and monoascospore cultures and to derive ascospore progeny. In this study, however, a mixed suspension of microconidia, macroconidia and mycelial fragments from each isolate was used as the 'male' parent to spermatize the sclerotia of each 'female' parent. In each pairwise combination, the two isolates were selfed and used as both male and female parent in sexual crosses. Sclerotia that were not spermatized, and sclerotia that were massspermatized by all the strains involved in the mating experiment, were used as controls. Three replicate cultures on quartz sand kept in a growth chamber for 4 months were used to determine mating reactions. During this period, the presence of primordia and apothecia was checked weekly.

In additional experiments, two standard reference strains (see below) were used to determine the sexual compatibility of unclassified isolates, using the improved method of Faretra et al. (1988). Each isolate was paired with the reference strains, both as sclerotial and as spermatizing partner, and unspermatized sclerotia were used as the controls. Observations were made at $7 \mathrm{~d}$ intervals during 3 months exposure of sclerotia to visible light.

\section{RESULTS AND DISCUSSION}

The results of the mating experiments showed that most field isolates (Table 1) and all ascospore isolates (Table 2) were self-sterile. With only one exception, the isolates could be divided into two groups on the basis of their intra-group sterility and inter-group fertility (Tables 1 and 2). An exceptional isolate, WS180, was self-fertile and cross-fertile with all other isolates with the exception of WS169 (Table 1).

The connection between compatibility groups of field isolates and ascospore isolates was investigated by intercrossing representative cultures. Isolates WS55 and SAS56, and WS158 and SAS405, formed two compatibility groups displaying intra-group sterility and inter-group 
Table 1. Mating reactions observed in reciprocal crosses between field isolates of Botrytis cinerea

+ , Fertile mating (i.e. apothecia produced); - , sterile mating; MSP, mass-spermatized sclerotia; USP, unspermatized sclerotia. Matings enclosed in blocks are those predicted to be fertile by a simple mechanism of bipolar heterothallism. The WS55 isolate was from rose and the others from grapevine. Based on three replicates of each cross.

\begin{tabular}{|c|c|c|c|c|c|c|c|c|c|c|c|c|c|c|}
\hline \multicolumn{15}{|c|}{ Male parent (spermatia) } \\
\hline & wsss & wS76 & WS 102 & WS 119 & wS 138 & wS165 & wS169 & wS 177 & ws 131 & wS15s & wS158 & ws 180 & MSP & USP \\
\hline wsss & - & - & - & - & - & - & - & - & + & + & + & + & + & - \\
\hline WS76 & - & - & - & - & - & - & - & - & + & + & + & + & + & - \\
\hline ws 102 & - & - & - & - & - & - & - & - & + & - & + & - & + & - \\
\hline ws 19 & - & - & - & - & - & - & - & - & + & + & + & + & + & - \\
\hline ws 138 & - & - & - & - & - & - & - & - & - & - & + & + & + & - \\
\hline ws 165 & - & - & - & - & - & - & - & - & - & + & - & - & - & - \\
\hline ws169 & - & - & - & - & - & - & - & - & + & + & - & - & - & - \\
\hline WS177 & - & - & - & - & - & - & - & - & + & - & + & - & + & - \\
\hline wS13! & + & + & + & + & + & + & + & + & - & - & - & + & + & - \\
\hline ws 155 & + & + & + & + & + & + & + & + & - & - & - & - & + & - \\
\hline wS158 & + & + & + & + & + & + & + & + & - & - & - & + & + & - \\
\hline wS180 & - & + & + & - & + & + & - & + & - & + & + & + & + & + \\
\hline
\end{tabular}

fertility. Consequently, most isolates, irrespective of origin, could be assigned to one of two compatibility groups.

These results indicate that a single locus with two alleles controls mating type in Botryotinia fuckeliana. Our findings and conclusion are in agreement with those of Groves \& Loveland (1953). Using the nomenclature suggested by Yoder et al. (1986), the locus has been designated $M A T 1$; the $M A T 1-1$ allele has been assigned to isolate SAS56 and the MAT1-2 allele to isolate SAS405. Isolates SAS56 and SAS405 were used as reference strains to determine the mating type of all other isolates used in this study.

This genetic explanation was reinforced by the $1: 1$ segregation of the MAT1-1:MAT1-2 mating type difference among the combined ascospore progeny of 24 different crosses (Table 3 ). However, a few monoascospore cultures were sexually compatible with both the MAT1-1 and $M A T 1-2$ reference strains and produced apothecia from unspermatized sclerotia; these cultures were designated $M A T 1-1 / 2$ (Table 3).

Out of 213 field isolates of Botrytis cinerea tested for mating type, 99 were classified as $M A T 1-1,80$ as $M A T 1-2$, and 34 as $M A T 1-1 / 2$ (Table 4). The $M A T 1-1 / 2$ isolates were frequently self-fertile. There was no obvious correlation between an isolate's mating type and its morphology or its ability to produce sclerotia and apothecia (Table 4).

Ten monoconidial progeny were derived from each of six homothallic (i.e. self-fertile) field isolates and tested for mating type. The results of these tests (Table 5) showed that cultures originating from single macroconidia can be either homothallic $(M A T 1-1 / 2)$ or heterothallic (MAT1-1 or $M A T 1-2)$. This indicates that segregation of compatibility determinants occurs during conidiogenesis, so that either or both alleles of the mating-type gene can be present in a conidium. 
Table 2. Mating reactions observed in reciprocal crosses between monoascospore isolates of Botrytis cinerea

+, Fertile mating (i.e. apothecia produced); - , sterile mating; MSP, mass-spermatized sclerotia; USP, unspermatized sclerotia. Matings enclosed in blocks are those predicted to be fertile by a simple mechanism of bipolar heterothallism. Based on three replicates of each cross.

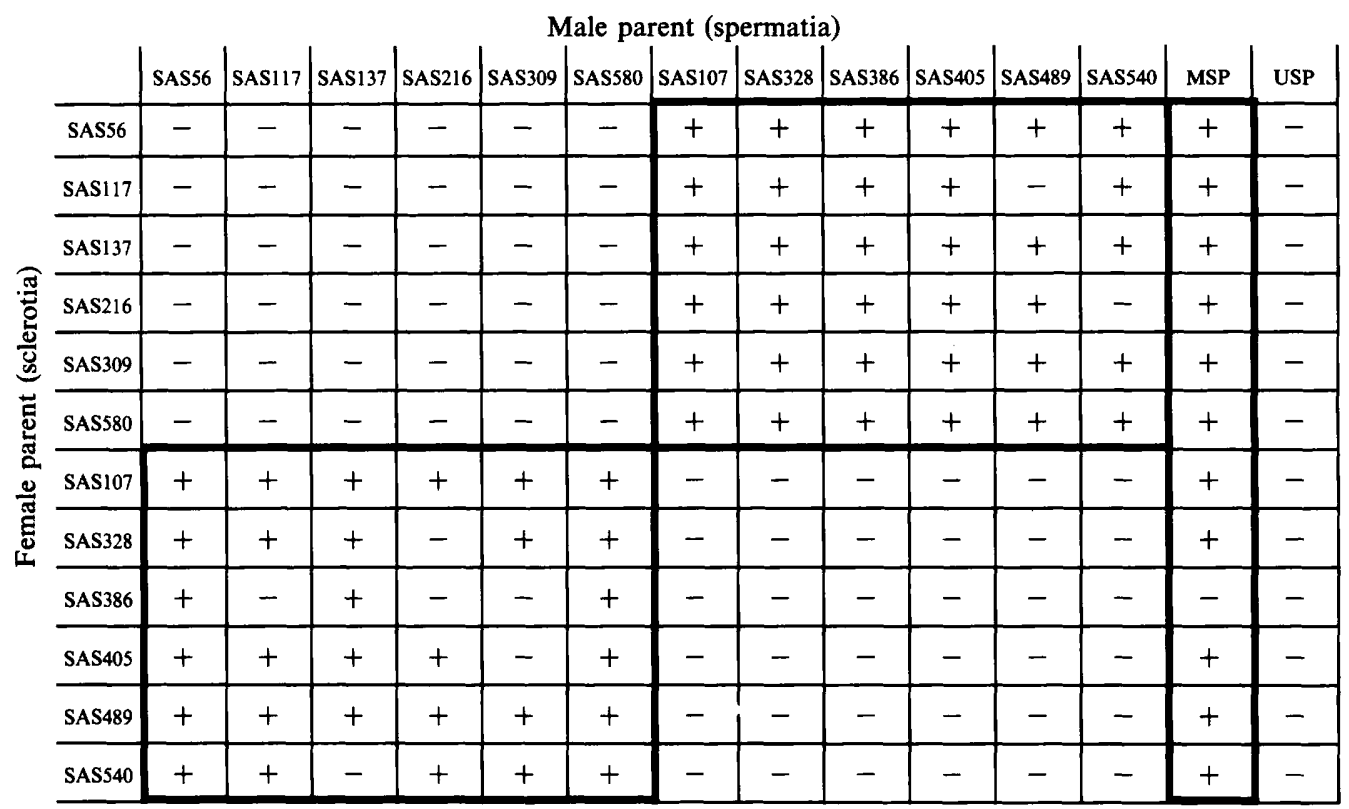

In our study, the apothecia of Botryotinia fuckeliana originated exclusively from sclerotia. It is probable, therefore, that the sclerotia are an essential part of the life cycle required for sexual reproduction. Although isolates unable to produce sclerotia did not function as female parents in sexual crosses, our data show that this is not a complete barrier to outcrossing, because the microconidia and the vegetative cells of the same isolate were always successful as male gametes in crosses with compatible isolates. The typical, sclerotia-forming, isolates were usually able to function as both male and female parents in sexual crosses.

The phenotypes of field isolates were very variable under laboratory conditions, depending on the medium, temperature, light and other environmental factors. Cultures maintained on aqueous media of ten lost the ability to produce sclerotia and apothecia. It is possible, therefore, that isolates unable to function as female (sclerotial) parents in the laboratory can do so under field conditions.

The sclerotia of some isolates were not able to germinate carpogenically even in compatible crosses. Bergquist \& Lorbeer (1972) observed a similar phenomenon in Botryotinia squamosa and hypothesized that such cultures carry one or more factors that interfere with the development of sclerotia and/or apothecial initials. In this investigation, segregation of such factors was not apparent among the offspring of matings in which these isolates acted as male parents. That is, we found no evidence of a simple major gene system responsible for this alteration in sclerotial development.

A few of the field isolates and monoascospore progeny were self-fertile and compatible with either of the two reference strains. Isolates of Botryotinia fuckeliana with similar properties were reported by Lorenz \& Eichhorn (1983). In Botryotinia squamosa, self-fertility of normally heterothallic isolates (i.e. secondary homothallism) has been ascribed by Lorbeer (1985) to the 
Table 3. Mating types of random ascospore progeny of field isolates of Botrytis cinerea

Mating types were determined by crossing each progeny with reference strains SAS56 and SAS405. The data in parentheses show the number of progeny that were able to produce apothecia. Ten progeny of each cross were analysed. $P\left(\chi^{2}=1.083\right)=0.70-0.80$ for $117: 109=1: 1$.

\begin{tabular}{llccc}
\multicolumn{1}{c}{ Origin of ascospores } & \multicolumn{3}{c}{ Mating type } \\
$\begin{array}{c}\text { O parent } \\
\text { (sclerotia) }\end{array}$ & $\begin{array}{c}\text { o parent } \\
\text { (spermatia) }\end{array}$ & MAT1-1 & $M A T 1-2$ & $M A T 1-1 / 2$ \\
WS55 & WS131 & $4(4)$ & $4(4)$ & $2(2)$ \\
WS55 & WS155 & $3(3)$ & $4(4)$ & $3(3)$ \\
WS55 & WS158 & $1(1)$ & $8(8)$ & $1(1)$ \\
WS76 & WS155 & $4(3)$ & $5(5)$ & $1(1)$ \\
WS76 & WS158 & $1(0)$ & $8(3)$ & $1(1)$ \\
WS102 & WS158 & $7(6)$ & $3(3)$ & 0 \\
WS119 & WS131 & $4(3)$ & $6(3)$ & 0 \\
WS119 & WS155 & $4(3)$ & $6(5)$ & 0 \\
WS119 & WS158 & $5(4)$ & $5(5)$ & 0 \\
WS131 & WS55 & $6(6)$ & $2(2)$ & $2(2)$ \\
WS131 & WS76 & $7(7)$ & $3(3)$ & 0 \\
WS131 & WS138 & $6(5)$ & $4(4)$ & 0 \\
WS131 & WS165 & $5(4)$ & $5(3)$ & 0 \\
WS138 & WS158 & $5(5)$ & $4(4)$ & $1(1)$ \\
WS158 & WS55 & $7(7)$ & $3(3)$ & 0 \\
WS158 & WS76 & $6(6)$ & $4(3)$ & 0 \\
WS158 & WS119 & $7(5)$ & $3(2)$ & 0 \\
WS158 & WS138 & $6(6)$ & $4(4)$ & 0 \\
WS158 & WS165 & $5(3)$ & $5(5)$ & 0 \\
WS158 & WS177 & $5(5)$ & $5(5)$ & 0 \\
WS158 & WS180 & $6(5)$ & $4(3)$ & 0 \\
WS180 & WS76 & $5(2)$ & $3(3)$ & $2(2)$ \\
WS180 & WS138 & $3(2)$ & $6(4)$ & $1(1)$ \\
WS180 & WS155 & $5(3)$ & $5(3)$ & 0 \\
\cline { 2 - 3 } & & $117(98)$ & $109(91)$ & $14(13)$ \\
& & & &
\end{tabular}

presence of genetically different nuclei in heterokaryotic vegetative cells such as mycelium, conidia and sclerotia. The ability of Botrytis cinerea to produce heterokaryotic vegetative cells has been recognized since the classic study of Hansen \& Smith (1932). Heterokaryosis, therefore, provides a genetic explanation for secondary homothallism of field isolates and vegetative progeny of Botrytis cinerea. But it does not account satisfactorily for the self-fertility of monoascospore isolates, as it is unlikely that individual ascospores will contain more than one nuclear genotype. In fact, it has been observed that during ascus development in Botryotinia fuckeliana a single nucleus is included in each ascospore (Lorenz \& Eichhorn, 1983; Faretra \& Antonacci, 1987).

Various genetic mechanisms are known to underlie secondary homothallism in heterothallic fungi. Examples include: regular inclusion in each ascospore of two nuclei carrying opposite compatibility alleles, such as occurs in some four-spored ascomycetes (Dodge, 1927; Franke, 1957); coexistence of mating type determinants in heteroploid isolates (for a review see Tolmsoff, 1983); mutation of the mating-type gene, as in filamentous ascomycetes, e.g. Glomerella cingulata (Stonon.) Spauld. et Schrenk (Wheeler, 1950), and the ascospore dimorphic Cromocrea spinulosa Seaver (Mathieson, 1952) and Sclerotinia trifoliorum Erikss. (Uhm \& Fujii, 1983); and transposition of mating-type genes, as in yeasts (Beach et al., 1982; Egel, 1977, 1984; Egel \& Gutz, 1981; Haber, 1983). It is also possible that irregularities during meiosis affect the distribution of nuclei into ascospores. Further study of monoascospore isolates is needed to reveal whether any of these genetic processes is responsible for secondary homothallism in Botryotinia fuckeliana. In fact, more cytological studies of asci of known parentage, analysis of 
Table 4. Source, morphology and mating type of field isolates of Botrytis cinerea

Source of isolates*
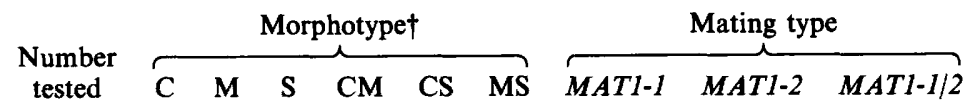

Anthirrhinum majus L.

Azalea spp.

Carica pentagona $\mathrm{Hb}$.

Chrysanthemum spp.

Cucumis sativus L.

Cucurbita pepo var. italica $\mathrm{L}$.

Cynara scolymus $\mathbf{L}$.

Daucus carota $\mathbf{L}$.

Dianthus caryophyllus L.

Ficus elastica Roxb.

Fragaria vesca $\mathrm{L}$.

Freesia spp.

Gerbera spp.

Gladiolus spp.

Helianthus annuus $\mathrm{L}$.

Hibiscus spp.

Lactuca sativa $\mathrm{L}$.

Lilium spp.

Limonium spp.

Lycopersicon esculentum Mill.

Pelargonium spp.

Philodendron spp.

Prunus avium L.

Prunus dulcis (Mill.) Webb.

Prunus persica (L.) Stokes

Pyrus communis L.

Rosa spp.

Rubus fruticosus $\mathrm{L}$.

Strelitzia reginae Bank

Tulipa spp.

Vitis vinifera $\mathrm{L}$.

Unknown

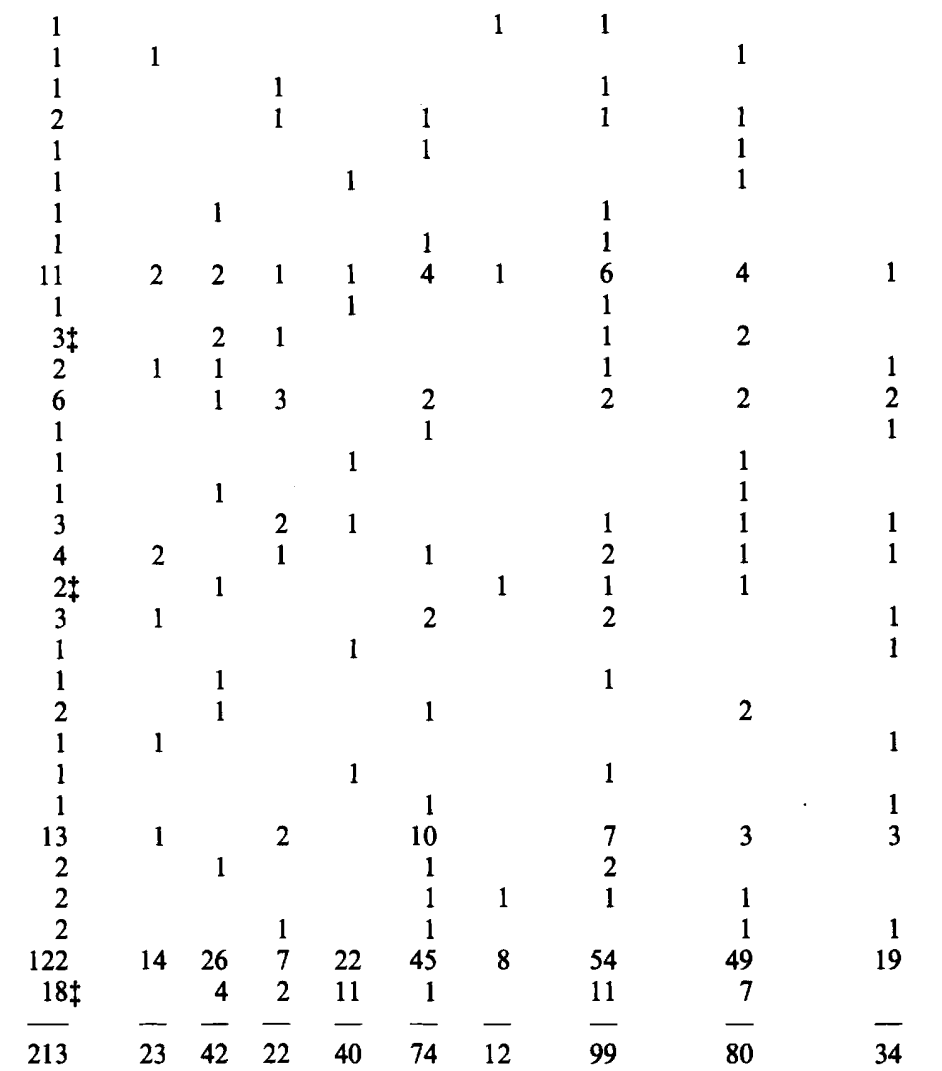

* Naturally-infected host plants from which isolates were obtained. Most of them were located in Apulia and Basilicata, the others in Piedmont, Sardinia, and Sicily.

†C, conidial; M, mycelial; S, sclerotial; CM, conidial-mycelial; CS, conidial-sclerotial; MS, mycelialsclerotial.

$\ddagger$ Cultures supplied by the Istituto di Patologia vegetale of Turin.

Table 5. Mating types of monoconidial progeny of homothallic field isolates of Botrytis cinerea

\begin{tabular}{cccc} 
& \multicolumn{3}{c}{ Mating type of progeny* } \\
\cline { 2 - 4 } Field isolate & MAT1-1 & MAT1-2 & MAT1-1/2 \\
WS64 & 10 & 0 & 0 \\
WS92 & 3 & 0 & 7 \\
WS180 & 4 & 1 & 5 \\
WS184 & 0 & 0 & 10 \\
WS185 & 9 & 0 & 1 \\
WS187 & 0 & 7 & 3
\end{tabular}

* Ten progeny of each field isolate were analysed. 
monoascospore progeny of homothallic and heterothallic strains carrying genetic markers, and careful observation on the segregation of $M A T 1$ gene from heterokaryons should help to clarify the question.

Apothecia of Botryotinia fuckeliana appear to be rare in nature (Grindle, 1979). Our survey of natural populations of Botrytis cinerea in Italy has shown that field isolates of this pathogen from different host plants in the same or neighbouring locations frequently carry opposite alleles of the $M A T 1$ mating-type gene. It seems unlikely, therefore, that the rarity of apothecia is due to the rarity of compatible isolates that can generate sexual progeny when intercrossed. Furthermore, some of the field isolates were homothallic, having the ability to produce apothecia without cross-fertilization. These observations show that sexual reproduction is potentially an effective and widespread method for releasing new genetic variants of Botrytis cinerea into natural populations where prevailing environmental conditions are conducive to differentiation of sclerotia and their carpogenic germination.

The production of apothecia under laboratory conditions is a slow and tedious process. Nevertheless, our studies have resulted in a reliable method for detecting sexually compatible isolates and obtaining sexual progeny from crosses of diverse parents. It should now be possible to carry out detailed genetic analysis of this important plant pathogen, which has remained virtually unexplored at the genetic level since its teleomorphic stage was first obtained in culture by Groves \& Drayton (1939).

This work was supported by a grant from Ministero della Pubblica Istruzione (MPI $40 \%$ ) 'Resistenza di crittogame ai funghicidi'.

The authors wish to thank Dr M. Grindle, Department of Genetics of the University of Sheffield, UK, for the revision of the manuscript and his helpful criticism.

\section{REFERENCES}

Beach, D., Nurse, P. \& Egel, R. (1982). Molecular rearrangement of mating-type genes in fission yeast. Nature, London 296, 682-683.

BERGQuist, R. R. \& LoRBEer, J. W. (1972). Apothecial production, compatibility and sex in Botryotinia squamosa. Mycologia 64, 1270-1281.

BuchWALD, N. F. (1953). Botryotinia (Sclerotinia) globosa sp.n. on Allium ursinum, the perfect stage of Botrytis globosa Raabe. Phytopathologische Zeitschrift 20, 241-254.

COE, D. M. (1944). Variation in single ascospore isolates of Sclerotinia sclerotiorum. Mycologia 36, 234-241.

DODGE, B. O. (1927). Nuclear phenomena associated with heterothallism and homothallism in the ascomycete Neurospora. Journal of Agricultural Research 35, 289-305.

DraYton, F. L. (1932). The sexual function of the microconidia in certain Discomycetes. Mycologia 24, 345-348.

Drayton, F. L. (1937). The perfect stage of Botrytis convoluta. Mycologia 29, 305-318.

Drayton, F. L. \& Groves, J. W. (1943). A new Sclerotinia causing a destructive disease of bulbs and legumes. Mycologia 35, 517-528.

Drayton, F. L. \& Groves, J. W. (1952). Stromatinia narcissi, a new, sexually dimorphic, Discomycete. Mycologia 44, 119-140.

EGEL, R. (1977). 'Flip-flop' control and transposition of mating-type genes in fission yeast. In $D N A$ Insertion Elements, Plasmids and Episomes, pp. 447445. Edited by A. Bukhari, J. Shapiro \& S. Adhya. Cold Spring Harbor, NY: Cold Spring Harbor Laboratory.
EGEL, R. (1984). The pedigree pattern of mating-type switching in Schizosaccharomyces pombe. Current Genetics 8, 205-210.

EGEL, R. \& GUT2, H. (1981). Gene activation by copy transposition in mating-type switching of a homothallic fission yeast. Current Genetics 3, 5-12.

ELLioTT, M. E. (1964). Self-fertility in Botryotinia porri. Canadian Journal of Botany 42, 1393-1395.

EzEKIEL, W. N. (1924). Fruit-rotting Sclerotinias. II. The American brown-rot fungi. Maryland Agriculture Experimental Station Bulletin 271, 87-142 (quoted by Willets \& Harada, 1984).

FARETRA, F. \& ANTONACCI, E. (1987). Production of apothecia of Botryotinia fuckeliana (de Bary) Whetz. under controlled environmental conditions. Phytopathologia mediterranea 26, 29-35.

Faretra, F., ANTONacCi, E. \& Pollastro, S. (1988). Improvement of the method used for obtaining apothecia of Botryotinia fuckeliana (Botrytis cinerea) under controlled conditions. Annali di microbiologia ed enzimologia 38 (in the Press).

Franke, G. (1957). Die Cytologie der Ascusentwicklung von Podospora anserina. Zeitschrift Vererbungslehre 88, 159-160.

GoDFREY, G. H. (1923). Gray mold of castor bean. Journal of Agricultural Research 23, 679-716.

GrINDLE, M. (1979). Phenotypic differences between natural and induced variants of Botrytis cinerea. Journal of General Microbiology 111, 109-120.

Groves, J. W. \& Bowerman, C. A. (1955). Sclerotinia borealis in Canada. Canadian Journal of Botany 33, 591-594.

Groves, J. W. \& Drayton, F. L. (1939). The perfect stage of Botrytis cinerea. Mycologia 31, 485-489. 
Groves, J. W. \& ElliotT, M. E. (1961). Self-fertility in the Sclerotiniaceae. Canadian Journal of Botany 39, 215-231.

Groves, J. W. \& Loveland, C. A. (1953). The connection between Botryotinia fuckeliana and Botrytis cinerea. Mycologia 45, 415-425.

HABER, J. E. (1983). Mating-type genes of Saccharomyces cerevisiae. In Mobile Genetic Elements, pp. 559-619. Edited by J. A. Shapiro. London: Academic Press.

Hansen, H. N. \& Smith, R. E. (1932). The mechanism of variation in imperfect fungi: Botrytis cinerea. Phytopathology 22, 953-964.

HARADA, Y. (1977). Studies on the Japanese species of Monilinia (Sclerotiniaceae). Bulletin of the Faculty of Agriculture, Hirosaki University 27, 80-109.

HENNEBERT, G. L. (1973). Botrytis and Botrytis-like genera. Persoonia 7, 183-204.

HenNebert, G. L. \& Groves, J. W. (1963). Three new species of Botryotinia on Ranunculaceae. Canadian Journal of Botany 41, 341-370.

Henson, L. (1935). Apothecium production in Sclerotinia trifoliorum and Sclerotinia sclerotiorum. Phytopathology 25, 19-20 (abstract).

KEAY, M. A. (1939). A study of certain species of Sclerotinia. Annals of Applied Biology 27, 227246.

LORBEER, J. W. (1980). Variation in Botrytis and Botryotinia. In The Biology of Botrytis, pp. 19-39. Edited by J. R. Coley-Smith, K. Verhoeff \& W. R. Jarvis. London: Academic Press.

LORBEER, J. W. (1985). Genetics of Botryotinia (Botrytis) squamosa. 8th Botrytis Symposium, Alba, Italy, 813 September 1985.
LORENZ, D. H. \& EichHoRN, K. W. (1983). Untersuchungen an Botryotinia fuckeliana Whetz., dem Perfektstadium von Botrytis cinerea Pers. Zeitschrift für Pflanzenkrankheiten und Pflanzenschutz 90, 1-11.

MathIESON, M. J. (1952). Ascospore dimorphism and mating type in Cromocrea spinulosa (Fuckel) Petch n. comb. Annals of Applied Biology, N.S. 16, 449-467.

PaUl, W. R. C. (1929). A comparative morphological and physiological study of a number of strains of Botrytis cinerea Pers. with special reference to their virulence. Transactions of the British Mycological Society 14, 118-135.

TOLMSOFF, W. J. (1983). Heteroploidy as a mechanism of variability among fungi. Annual Review of Phytopathology 21, 317-340.

UHM, J. Y. \& FUJI, H. (1983). Heterothallism and mating type mutation in Sclerotinia trifoliorum. Phytopathology 73, 569-572.

WHEELER, H. E. (1950). Genetics of Glomerella. VIII. A genetic basis for the occurrence of minus mutants. American Journal of Botany 37, 304-312.

WhETZEL, H. H. (1929). North American species of Sclerotinia. II. Two species on Carex, S. duriaeana (Tul.) Rehm, and S. longisclerotialis sp. n. Mycologia 21, 5-32.

WhETZEL, H. H. (1943). A monograph of Lambertella, a genus of brown-spored Discomycetes. Lloydia 6, 18-52.

WilletTs, H. J. \& HaRADA, Y. (1984). A review of apothecial production by Monilinia fungi in Japan. Mycologia 76, 314-325.

Yoder, O. C., Valent, B. \& Chumley, F. (1986). Genetic nomenclature and practice for plant pathogenic fungi. Phytopathology 76, 383-385. 